\title{
FOOD INSECURITY, HOARDING BEHAVIOR, AND ENVIRONMENTAL HARSHNESS DO NOT PREDICT WEIGHT CHANGES DURING THE COVID-19 PANDEMIC
}

\author{
Stephanie J. Eder ${ }^{1,2}$, Michal M. Stefanczyk ${ }^{3}$, Michal Pieniak ${ }^{3}$, Judit Martínez Molina ${ }^{4}$, Jakub \\ Binter ${ }^{5}$, Ondra Pešout ${ }^{6}$, Patrick Smela1, Frank Scharnowski ${ }^{7}$, David Steyrl ${ }^{7}$ \\ ${ }^{1}$ Department for Basic Psychological Research and Research Methods, University of Vienna, Austria \\ ${ }^{2}$ Urban Human, Vienna, Austria \\ 3Institute of Psychology, University of Wroclaw, Wroclaw, Poland \\ ${ }^{4}$ Faculty of Psychology, Universitat de Barcelona, Barcelona, Catalunya, Spain \\ 5 Faculty of Humanities, Charles University, Praha, Czech Republic \\ ${ }^{6}$ Department of Psychology, Jan Evangelista Purkyne University, Usti nad Labem, Czech Republic \\ 7Department of Cognition, Emotion, and Methods in Psychology, University of Vienna, Austria \\ ${ }^{8}$ Department of Psychiatry, Psychotherapy and Psychosomatics, Psychiatric Hospital, University of Zürich, \\ Switzerland \\ 9Neuroscience Center Zürich, University of Zürich and Swiss Federal Institute of Technology, Zürich, Switzerland \\ ${ }^{10}$ Zürich Center for Integrative Human Physiology (ZIHP), University of Zürich, Switzerland
}

Stephanie.eder@univie.ac.at

\begin{abstract}
The COVID-19 pandemic not only presents a medical and psychological stressor to many, but has also led to alterations that many perceived as threatening, such as reduced financial income and job insecurity. A symptom of collective worrying were so-called panic- or 'hamster' purchases, whereby people hoarded food following the introduction of governmental restrictions in response to the pandemic. This behavior indicated subjective 'food insecurity' in many individuals at a time when loss of income could potentially lead to real food insecurity for some. Since both perceived and actual food insecurity, as well as stress, are thought to facilitate weight gain as an adaptive response, this study aimed to investigate body weight during the pandemic. Specifically, we modeled the effects of both psychological and environmental factors such as food insecurity, hoarding behavior and loss of income, on body on weight as lockdown measures were introduced and loosened in four European countries. While we observe no systematic changes in body weight over the observed period, there was inter-individual variation in weight changes. However, contrary to our hypothesis, results show that neither food insecurity, hamster purchases, nor loss of income were predictors of weight change or weight/height ratio in our models, and none of our machine learning models outperformed a trivial predictor using the mean of all values for each prediction. In conclusion, this study does not add support for the notion that perceived food insecurity can predict weight gain or a higher weight/height ratio at a time of environmental uncertainties. This suggests that acute alterations in appetite reported upon triggering environmental harshness have no effect beyond that moment. Possibly life-history strategies acquired earlier in life remained stable during this crisis with respect to food consumption and weight.
\end{abstract}

Keywords: Life-history theory, Appetite, Food insecurity, Body mass, Weight gain, Environmental harshness, COVID-19. 


\section{INTRODUCTION}

\section{Pandemic phenomena}

In spring 2020, countries across the world faced one of the biggest acute crises in recent history. The spread of SARS-CoV2 causing the COVID-19 pandemic presented a medical and psychological stressor and led to governmental restrictions in an attempt to contain the infection rates. The severity of the outbreak differed across countries, whilst governmental as well as public reactions also varied (Petherick et al., 2020, BBC, 2020). Although some governments relied on rigorous rules and timely public information (Bui, 2020), it has been argued that some political leaders contributed to public confusion by providing suboptimal guidance (Kerri et al., 2020).

Severely hit countries, such as Spain, experienced a dramatic decrease in access to health care and a collapse of the funeral system (Enguix, 2020; Redacció i agèncie la Vanguardia, 2020), and declared a nationwide state of alarm (March 14th, Ministerio de la Presidencia, 2020) followed by strict curfews. Countries in the average of infection rates, such as Austria, also issued prescribed restrictions (Bundesministerium für Soziales, Gesundheit, Pflege und Konsumentenschutz [BSGPK], 2020), and even less affected countries such as Poland and Czech Republic relied on strict regulations and 'social isolation' to halt the spread (Dziennik Ustaw, 2020; Ministry of Health of the Czech Republic [MHCR], 2020).

The virus as a worldwide stressor along with the changes in everyday life lead to alterations in societal norms and psychological functioning. Curfews, travel restrictions, and physical distancing' deprived people living alone from the support of their family and friends. Prohibitions of gatherings including funerals make it harder for families to mourn their loved ones (Velásquez, 2020). In the general population, increases in anxiety and loneliness have been reported (Brooks et al., 2020; Mazza et al., 2020).

The negative impact of these events was manifested in behavioral changes, such as shifted preferences for movies (Scrivner, 2020) and the use of fewer positive words on social media (Computational Story Lab, 2020; see Dodds et al., 2011), but also substantial psychological problems (e.g. Kim et al., 2020). Another phenomenon that occurred at the beginning of the first curfews in some European countries were so called panic- or 'hamster-purchases' (Hamsterkauf, cf. Steger 2020): Durable food, such as rice and noodles, and - remarkably - toilet paper (Garbe et al., 2020), was bought in large quantities and stockpiled at home (Figure 1). This indicates subjective food and supply insecurity in parts of the population. However, with few exceptions (see Tondo, 2020), the actual availability of food was at no point restricted in Europe, even though economic changes due to the crisis may have caused actual uncertainties regarding the financing of previously spontaneous purchases (for reports of the global situation of food insecurity see UN, 2020). 

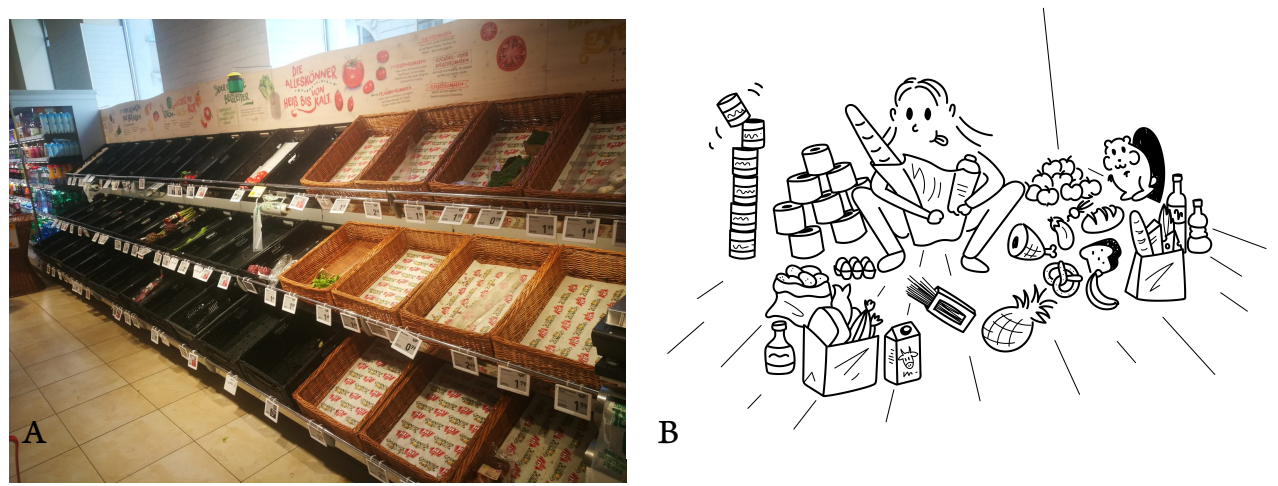

Figure 1: (A) Empty food racks in an Austrian store by the start of this study. (B) The term 'hamster purchases' refers to buying excessive amounts of food, typically for stockpiling them at home. Photo: SJE

\section{Food insecurity and environmental harshness}

Considerable research has evidenced that food insecurity is linked to obesity, and weight gain may be an adaptive response to threatened food supply (Dhurandhar, 2016). The link between weight and food insecurity is typically demonstrated for actual insecurity due to financial shortcomings, and has been explained by life-history strategies (Nettle, 2010). Life-history theory provides a framework for explaining persistent patterns over an individual's lifespan, such as how to allocate limited resources, as strategies to cope with specific environmental conditions (cf. Del Giudice et al., 2016). For example, experiences of environmental harshness favor the adoption of faster lifehistory strategies, leading to earlier reproductive ages and less investment in future opportunities. A 'harsh' environment is described as an environment with scarce resources, higher competition, and many pathogens or other threats, altogether often summed up in higher levels of mortality (Brumbach et al., 2009) or lower socioeconomic status (Griskevicius et al., 2013). Social factors, such as infant-parent attachment security, have also been found to affect life-history strategies (Belsky et al., 2010), and as such, they have been shown to predict children's obesogenic behavior (Lamson et al., 2019). Applying life-history theory to eating behavior implies that in response to anticipated environmental scarcity or insecurity, currently available resources should be fully exploited and stored as 'buffer fat' (Insurance hypothesis, Nettle et al., 2017). Whilst the practical implications of these theories have been confirmed by a large meta-analysis, the effects only seem to hold up for women (Nettle et al., 2017). Nettle and colleagues (2019) show that childhood experiences and the current food insecurity interact to influence body weight and higher caloric consumptions. Potential proximate explanations come from neuroscientific studies which show that neighborhood deprivation alters children's recruitment of motivational neurocircuits in an incentive-delay task (Mullins et al., 2020). These neurological responses could lead to higher impulsivity and more immediate resource use when compared to children from areas without deprivation. Lack of financial resources has been linked more directly to desire for food as well: desire for money links to higher caloric consumptions, and satiety to more financial generosity (Briers et al., 2006).

Life-history strategies can also be adjusted over time to fit a current situation (Vigil \& Geary, 2006), and even acute activation of thoughts on environmental harshness have been found to increase appetite, more specifically, appetite for high-caloric foods (Laran \& Salerno, 2013). Similar approaches investigated food preferences and found increased desire for foods with higher energy density when participants were primed with scenarios of economic and social harshness (Swaffield \& Roberts, 2015; cf. Theory of optimal foraging, see Lieberman, 2006). Furthermore, 
both acute stress and baseline anxiety have been linked to variations in gustatory thresholds (IleriGurel et al., 2013), which might explain some of the above effects on a physiological level.

However, whilst the comparative studies investigating real life environments focused on differences between neighborhoods, and experimental studies artificially and briefly changed the context using psychological triggers, actual environmental changes over time and their influence on weight or eating behavior are still relatively unexplored.

\section{Other factors: Sports, Sex and Stress}

Environmental harshness and food insecurity are not the only factors contributing to weight gain. Independent of panic-purchases, shopping behavior in general has been linked to weight status, as obese individuals and those classified as in a healthy weight range respond differently to deprivation versus satiety when shopping (Nisbett \& Kanouse, 1969). Another important contributor to body composition is physical activity, although the effects on overall weight gain can be positive or negative (Boyce et al., 2008, Fogelholm, 2000). Notably, exercising has not been unaffected by the COVID-19 pandemic either, as sport facilities closed in spring 2020 in many European countries (e.g. BSGPK, 2020; Dziennik Ustaw, 2020; MHCR, 2020; Ministerio de la Presidencia, 2020). More generally, eating behavior and weight is affected by stress (Geiker et al., 2017; Michaud et al., 1990; Popper et al., 1989), and may thus be affected by a world-wide stressor such as the 'corona-crisis'. However, feeding behavior is not equally affected by acute and chronic stress, nor do the same stressors elicit the same eating reactions in different individuals (Torres \& Nowson, 2007). One factor that has been repeatedly linked to reduced stress resistance and general anxiety is low attachment security (Simpson \& Rholes, 2017; cf. Simpson, \& Belsky, 2008), a pattern influenced by early life experiences that can extend well into adulthood (Hazan \& Shaver, 1987). Thus, the perception of environmental stressors may interact with such expectations concerning the outcome and value of social interactions. Furthermore, social support, which may be partly restricted by curfews, helps coping with stress (Heinrichs et al., 2003), and activating attachment stress led to higher caloric intake in both stress-eaters and stressundereaters (Emond et al., 2016). Similarly, threats to feeling of belonging induce differential preferences for 'comfort food' depending on attachment styles (Troisi et al., 2015). Sexual behavior, too, has been linked to both stress and body weight in humans, specifically, perceived weight status seems to interact with the amount of sexual activity (Akers et al., 2009; Leech et al., 2012) and internal stress is known to cause sexual problems and lessened sexual desire (Bodenmann et al., 2006). In turn, sexual activity attenuates the effects of stress in other species under controlled experimental conditions (Retana-Márquez et al., 2014).

\section{The current research}

The COVID-19 pandemic in spring 2020 along with the diverging trajectories of pathogenic threat and stringency of governmental responses in European countries allows to examine the relationships between stressors such as worrying about resource shortage, financial threats and environmental harshness, as well as physical activity, attachment security and sexual activity on weight. The present study investigates participants from Austria, Poland, Spain and Czech Republic over seven weeks, precisely as curfews and other strict legal measures were implemented and phased out in these countries. Because these are complex interactions of different interindividual factors, they require analytical approaches that can capture such dependencies. To meet these requirements, we used machine learning models which aim for predicting weight changes from the above-mentioned factors in our cross-national sample. We hypothesized that our machine-learning models will learn to predict weight changes, and expect that the input factors 'food insecurity', 'hoarding behavior', 'perceived threat of the virus', 'change in physical exercise', 
'environmental factors' such as the stringency of governmental responses, and 'spread of the virus' have a predictive value.

\section{METHODS}

Details concerning procedure, analysis and variables have been described previously and are accessible online (see https://osf.io/db4px/; Eder et al., 2020, August 22; Eder et al., 2020, September 14).

\section{Participants}

Our final sample consisted of 468 adult participants (mean age $=30.74$; SD age $=12.16 ; 344$ female), who repeatedly participated over a 7 -week period ( $\mathrm{N}=1522$ surveys). Cases with missing variables had to be excluded for the machine learning analyses. Our sample comprised participants from Austria $(n=167$, mean age $=31.02$; SD age $=12.22 ; 111$ female), Poland $(n=$ 125 , mean age $=26.24$; $\mathrm{SD}$ age $=8.34 ; 109$ female $)$, Spain $(\mathrm{n}=91$, mean age $=34.50 ; \mathrm{SD}$ age $=$ $13.95 ; 68$ female $)$ and Czech Republic $(n=44$, mean age $=36.97$; SD age $=15.93$; 29 female $)$. Additionally, 39 participants residing in other countries (Germany, United Kingdom, Ireland and Italy) filled in surveys (mean age $=25.47$; $\mathrm{SD}$ age $=5.48 ; 28$ female).

\section{Procedure}

For seven weeks, we sent out surveys via e-mail to participants who had been recruited over social media. They received no monetary incentives to participate in the study, but they were informed that their participation would be valuable for scientific research. They were also informed that they could drop out at any point. Self-reported weight and height was assessed at the beginning and the end of this period, whereas other variables (such as fear) were collected on a weekly basis. All communication with the participants took place in the national language of each country.

\section{Timeframe and political situation}

Administration of our surveys occurred during a phase when all observed countries had already implemented various measures to fight the spread of the virus and had varying case numbers of COVID-19. The first questionnaire was sent out to all participating countries during the week of March $16^{\text {th }}$ to $22^{\text {nd }}$, and the final questionnaire was to be completed in the week of April $27^{\text {th }}$ to May $3^{\text {rd }}$, 2020. The actual spread and effects of the virus, as well as the defensive measures taken to counteract the virus, differed between the observed countries. Importantly, this range allowed us to optimally examine the predictive validity of environmental features.

\section{Variables}

Due to the curfews in response to the pandemic, all data were collected as self-report measures. Our outcome variables, weight (reported in kilogram, as is habitual in health contexts) and height (reported in $\mathrm{m}$ and $\mathrm{cm}$ ), were assessed at the beginning and end of the seven-week period. Additionally, participants were asked to fill in the Perceived Vulnerability to Disease Scale (PVD, Duncan et al, 2009) and the Experiences in Close Relationships Revised (ECR-R, Fraley et al, 2000; Polish: Lubiewska et al, 2016; Czech: Cígler et al, 2019; Spanish modified from: FernándezFuertes et al, 2011) at two different points in time (four weeks apart). If not available in a 
country's language, the questionnaire was translated by a native speaker and reviewed by another native speaker. We also collected data on perceived threat of the virus, perceived economic threat of the measures, perceived health, physical activity, sexual encounters, as well as demographic items such as sex, sexual orientation, relationship status, and country of residence. For each week and country, we also included the stringency index describing the stringency of governmental measures as reported by Petherick et al. (2020), as well as confirmed cases and deaths per million citizens (Sources: Eurostat 2020; Hale et al., 2020).

\section{Analysis}

We fit linear (LASSO [least absolute shrinkage and selection operator], Tibshirani, 1996) and non-linear (ET [Extremely Randomized Trees], Geurts et al., 2006) machine learning models trying to predict change in weight over time. As a non-longitudinal follow up including more participants of the same sample, we apply the same models not to the change in weight over time, but to overall body weight (normalized by body height, similar to the often cited body-mass-index $[\mathrm{BMI}])$. The models were evaluated with nested stratified cross-validation $(90 / 10,100$ iterations each; Cawley \& Talbot, 2010), controlling for participant ID to counteract subject cluster learning. These sensitive methods allow to efficiently include many input variables without the danger of over-fitting to the data, and the non-linear models are capable of capturing even complex interactions between multiple input variables if they exist. We compared the models' performance to a trivial predictor, which uses the mean of all target variables for each prediction. To estimate the predictive value of the input features, we report the median permutation feature importance (PFI) for the better-performing model as the proportional loss of explained variance if the input is replaced by a random (non-informative) array of that variable (Breiman, 2001). This allows relatively confident statements even about the non-importance of an input factor.

Analyses were conducted in Python 3.7.7. (Scikit-learn 0.22.2., Pedregosa et al., 2011), IBM SPSS Statistics (version 25.0) and R (R Core Team, 2017).

\section{RESULTS}

\section{Popular resources}

$37 \%$ of the participants in our sample reported to have made at least one 'hamster-purchase'. In addition to hoarding food, $29.14 \%$ of the participants bought excessive amounts of drugs, and $26.50 \%$ toilet paper.

\section{Slight decrease in fear}

Over the course of the seven weeks, the fear of existential economic losses remained fairly stable, whereas there was a slight decrease in mean fear of the virus and fear of shortages in supply (Figure 2), possibly indicating habituation. Actual environmental changes over the course of the study are depicted in Eder et al. (2020, August 22). 


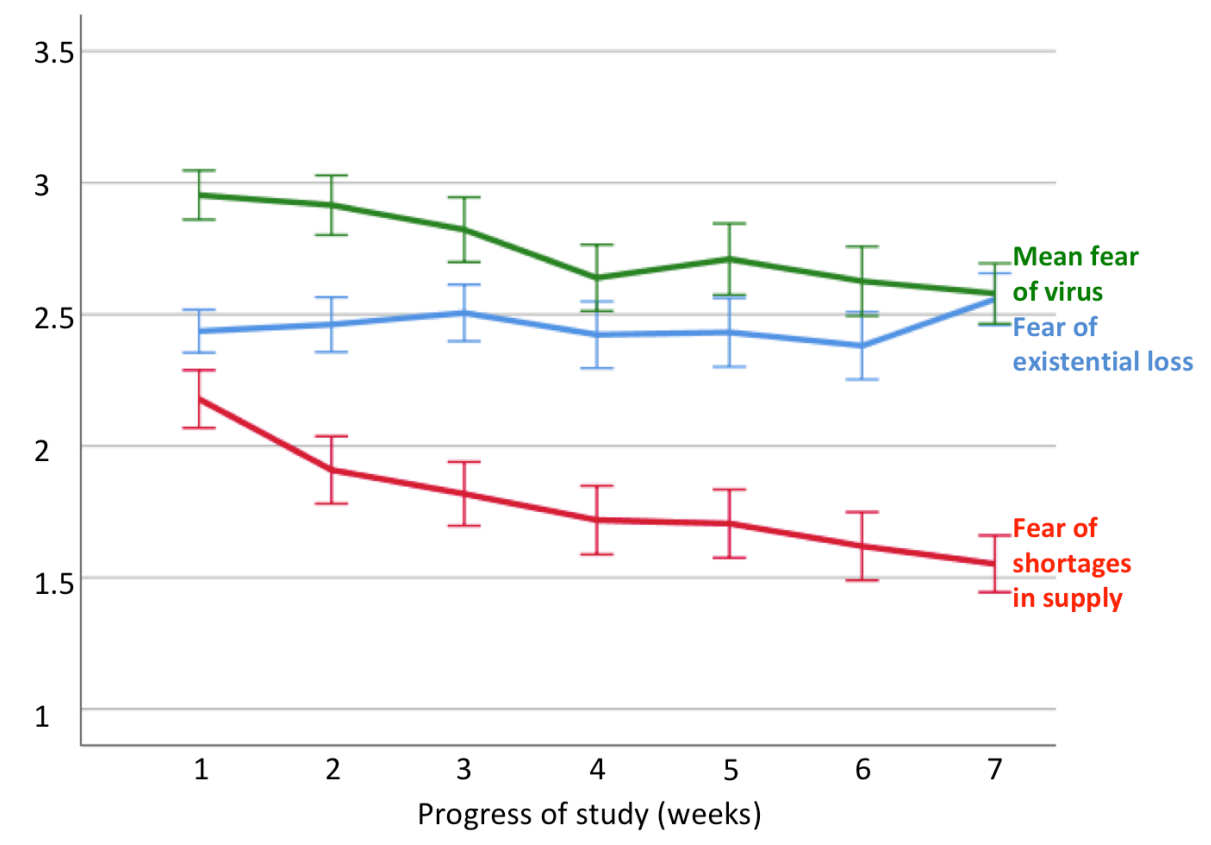

Figure 2: Over the course of the study, mean fear of the virus (green) and fear of shortages in supply (red) decreased, whereas the fear of existential economic losses (blue) remained fairly stable. Means and $95 \%$ confidence intervals depicted.

\section{No systematic differences in weight}

There were no significant overall differences in weight as reported at the beginning and the end of the lockdown $\left(\mathrm{M}_{\text {pre }}=64.49, \mathrm{SD}_{\text {pre }}=12.609, \mathrm{M}_{\text {post }}=64.79, \mathrm{SD}_{\text {post }}=12.841, \mathrm{t}(134)=-1.614, \mathrm{p}=\right.$ $0.109)$. Nevertheless, there was inter-individual variation in the constancy of participants' weight: $55 \%$ of participants reported a change in weight of at least 1kilogram (22\% a loss of weight, $33 \%$ a gain in weight).

\section{Predicting changes in weight and overall weight}

Inter-individual variation in weight change could not be predicted by our models better than by a trivial predictor (LASSO: $\mathrm{R}_{\text {avg }}=-0.24, p=1$; ET: $\mathrm{R}^{2}{ }_{\text {avg }}=-.30, p=1, \mathrm{~N}_{\text {participants }}=134, \mathrm{~N}_{\text {trials }}=732$ ).

We repeated our calculations including more participants with weight divided by height as a target variable. This target could not be predicted significantly better than with a trivial predictor, either, and the better performing model type would on average only have accounted for $3 \%$ of the variance in the data (LASSO: $\mathrm{R}_{\text {avg }}=0.03, p=.056$; ET: $\mathrm{R}_{\text {avg }}=-.03, p=.805, \mathrm{~N}_{\text {participants }}=468, \mathrm{~N}$ trials $=957)$. Figure 3 further illustrates that none of the models fit the data well, and that even in the best-performing models only changes in the predictor physical activity had a predictive value slightly above zero. Thus, the variables included in our machine learning models such as the fear that there may be shortcomings in food supplies, hoarding behavior, existential threat, sexual activity or case counts do not help to predict weight or weight changes during the lockdown in unknown participants. 

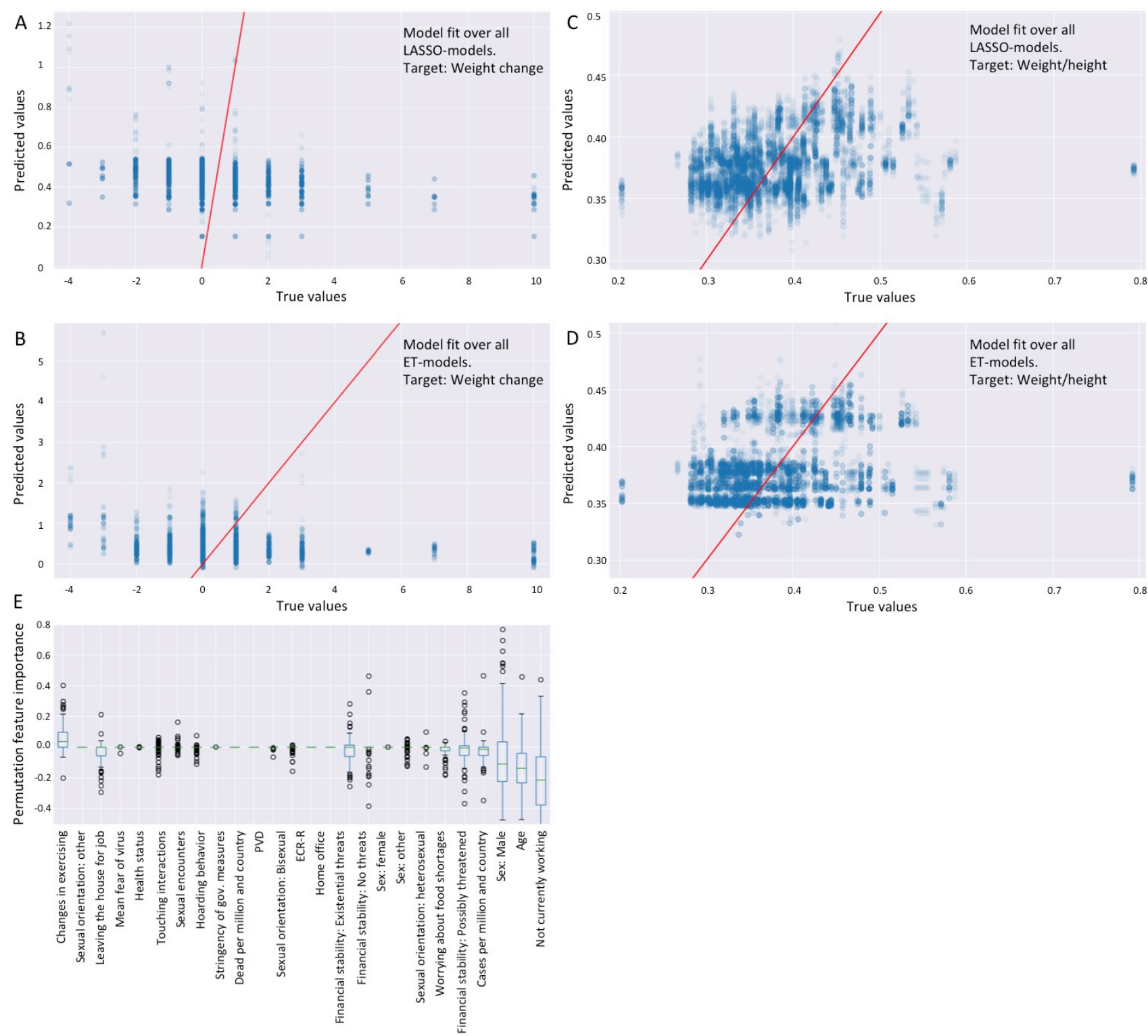

Figure 3: Illustration of the model fit of linear $(A, C)$ and non-linear $(B, D)$ models predicting participants' weight change $(A, B)$ and weight/height ratio $(C, D)$ by plotting predicted values in the testing sets against their true values: The closer the values lie to the red line, the better the prediction.(E) Boxplots of permutation feature importance the linear model predicting weight/ height ratio, depicting how much of the predicted variance is proportionally lost if a given feature is replaced by a random array of that feature (for categorical features, each category is listed). Only 'changes in exercising' has a median predictive value slightly greater than zero.

\section{DISCUSSION}

Influences of food insecurity, environmental harshness and stress on body mass have been welldocumented (Nettle et al., 2017; Torres \& Nowson, 2007). We hypothesized that worrying about resource shortage, hoarding behavior, loss of income and fear of the virus might be linked to 
weight change during nationwide movement restrictions and curfews. However, our sensitive machine learning analyses did not reveal any effects that any of the included features and their interactions might have on weight change or weight/height ratio. This indicates that either (1) other features that were not included in our models might contribute most to interpersonal variance in our outcome variables, (2) the outcome measures weight change and weight/height ratio are not sensitive enough over such a short time span, or (3) weight in a sample of young adults is not affected by the effects of the pandemic. Notably, internet-based recruitment of participants can lead to less representative samples of the included countries.

\section{Limitations of included features}

Perceived threats to supply in food, both throughout life and acute, and harsh environmental conditions have been linked to heightened caloric consumption and weight gain (e.g. Dhurandhar, 2016; Laran \& Salerno, 2013; Nettle et al., 2019; Swaffield \& Roberts, 2015). However, we find no link between weight or changes in weight and our measures of subjective food insecurity or environmental harshness, even if combined with other factors typically associated with body weight, such as physical activity (Boyce et al., 2008, Fogelholm, 2000). Furthermore, we included factors approximating the stress (cf. Geiker et al., 2017) triggered by the COVID-19 pandemic, namely the level of fear regarding the virus and threats by the restrictions, as well as factors that might modulate the relationship between stressor and stress response, such as social contact (Heinrichs et al., 2003), sexual behavior (Akers et al., 2009; Bodenmann et al., 2006) and attachment style (Emond et al., 2016; Simpson \& Rholes, 2017). Contrary to our expectations, neither an individual variable nor the interaction of those variables was of predictive value to interindividual variations in weight and weight change in any of our model types. One explanation for this is that the variables mostly influencing body mass are not included in our models. More candidate features obtained in Laboratory settings or by observations over a longer period of time should be included in future exploratory studies, for example reward sensitivity (e.g. Demos et al., 2012; Franken \& Muris, 2005) and childhood experiences of scarcity (Nettle et al., 2019).

Of course, weight alone is no conclusive measure on body composition (see Rothmann, 2008). We chose self-measured and self-reported overall body weight as the primary measurement because of its feasibility when investigating a large sample in times of curfews. Whilst self-reported weight has been shown to correlate with measured weight at an effect size of $\mathrm{R}=0.97$ in a large female sample, on average, weight was considerably underreported in that study (by 0.91 kilogram) (Luo et al., 2019). Here, at least some of the potential inaccuracies in participants' measurement of their own weight might have been mitigated by repeating the calculations with overall weight (a much higher figure) rather than the smaller changes in weight. Nevertheless, future studies relying on more meaningful methods such as body fat measurements (cf. Prentice, \& Jebb, 2001) may yield more informative results when investigating the relations between environmental factors, subjective food insecurity and 'buffer fat'.

Furthermore, one of our input features was the number of reported 'hamster purchases'. However, when asked which items were bought in large quantities, around a third of the hamsterbuyers reported to have bought non-edible items such as drugs or toilet paper. This suggests that the amount of those purchases extends beyond food insecurity, and reasons to purchase large amounts of groceries may not be fear of shortages, but simply avoiding leaving the house more often than necessary in times of a pandemic. The shortcomings of our variable 'hoardingbehavior' should, however, have been compensated by the variable directly asking for fear of shortcomings. 


\section{No changes in weight during the curfews}

We not only sought to predict variations in weight change, but altogether expected to find an influence of the pandemic and the unprecedented governmental regulations on weight in our sample.

However, we find no overall differences in body mass over the seven weeks. Thus, even if the 'corona-crisis' elicited acute or chronic stress, it did not affect overall mass in our sample. This is not expected given the many findings that link stressful periods to changes in body mass (Sinha \& Jastreboff, 2013; Torres \& Nowson, 2007), although the observed time period may have not been enough to capture the transition from high stress to chronic stress despite the decrease in mean fear. Nonetheless, $55 \%$ of individuals do show changes in weight, and in different directions: $22 \%$ reported to have lost at least one kilogram, 33\% had gained at least one kilogram.

Contrary to our hypotheses, food insecurity as well as actual and perceived environmental harshness could not explain these inter-individual differences, even though any notable differences between those groups should have been detected by our models. Importantly, our study deals with unique circumstances and is not immediately comparable to previous studies. Rather, our results shed light on relatively uninvestigated aspects of environmental harshness, stress and food insecurity. We investigate a less acute situation than the experiments by Laran and Salerno (2013), who demonstrate momentary shifts in appetite and preferences upon cues of environmental harshness; yet, our study spans a much shorter time period than studies focusing on mass development and caloric intake as a function of environmental harshness during development (Nettle et al., 2019). Therefore, our results provide insight on this middle ground and suggest that momentary changes due to triggers of scarcity are not enough to elicit actual changes in body mass.

A possible interpretation of these results is that early experiences of harshness and scarcity seem to drive fast life-history strategies well into adulthood (Griskevicius et al., 2013; Nettle, 2010), and, despite evidence for brief fluctuations (Laran \&Salerno, 2013), they seem to be stable against these short-term changes.

\section{Conclusion}

In conclusion, this study investigated changes in body mass over several weeks in four European countries, and was conducted during a time when the COVID-19 pandemic presented a worldwide stressor bringing about restrictions to autonomy and movement. Although the pandemic led to so-called panic-purchases at the beginning of the crisis, we found no evidence that hoarding behavior, subjective food insecurity or fear of the virus predict weight change or weight ratio. Our models do not significantly outperform a trivial predictor even if factors typically linked to body mass, such as exercising, are included. Our results indicate that reported acute changes in appetite and food preferences upon triggers of environmental harshness do not seem to influence individually acquired life-history strategies longer than for the moment, despite the continuous media coverage of the crisis. This is consistent with ideas that early experiences shape relatively stable life-history strategies. Future studies that take into account more informative outcome measures may help to clarify the influences of environment and subjective food insecurity on body composition in the light of flexible life-history strategies. 


\section{CONFLICT OF INTEREST AND TRANSPARENCY}

This research received no specific grant from any funding agency in the public, commercial or notfor-profit sectors. The Authors declare that there is no conflict of interest. The data set analyzed and presented in the current study is available on OSF (https://osf.io/afng3/).

\section{ETHICAL STATEMENT}

Data collection and analysis was conducted in accordance with the 1964 Helsinki declaration and later amendments, as well as national guidelines. Potentially intimate questions were additionally approved by the Institutional Review Board of Charles University, Faculty of Science.

\section{ACKNOWLEDGEMENTS}

We would like to thank two anonymous reviewers and the editor for their detailed remarks, which helped us to improve this manuscript. We would also like to thank Edward John Noon for his English-proofreading.

\section{FUNDING SUPPORT}

Frank Scharnowski was supported by the Swiss National Science Foundation (BSSG10_155915, 100014_178841, 32003B_166566), the Foundation for Research in Science and the Humanities at the University of Zurich (STWF-17-012), and the Baugarten Stiftung.

\section{REFERENCES}

Akers, A. Y., Lynch, C. P., Gold, M. A., Chang, J. C. C., Doswell, W., Wiesenfeld, H. C., Feng, W., \& Bost, J. (2009). Exploring the relationship among weight, race, and sexual behaviors among girls. Pediatrics, 124(5), e913-e920. DOI

BBC (2020, May 23rd). Coronavirus: Anti-lockdown car protest draws thousands. Retrieved from https:// www.bbc.com/news/world-europe-52783936

Belsky, J., Houts, R. M., \& Fearon, R. P. (2010). Infant attachment security and the timing of puberty: Testing an evolutionary hypothesis. Psychological Science, 21(9), 1195-1201. DOI

Bodenmann, G., Ledermann, T., Blattner, D., \& Galluzzo, C. (2006). Associations among everyday stress, critical life events, and sexual problems. The Journal of Nervous and Mental Disease, 194(7), 494-501. DOI

Boyce, R. W., Boone, E. L., Cioci, B. W., \& Lee, A. H. (2008). Physical activity, weight gain and occupational health among call centre employees. Occupational Medicine, 58(4), 238-244. DOI

Breiman, L. (2001). Random Forests. Machine Learning; 45, 5-32. DOI

Briers, B., Pandelaere, M., Dewitte, S., \& Warlop, L. (2006). Hungry for money: The desire for caloric resources increases the desire for financial resources and vice versa. Psychological Science, 17(11), 939-943. DOI

Brooks, S. K., Webster, R. K., Smith, L. E., Woodland, L., Wessely, S., Greenberg, N., \& Rubin, G. J. (2020). The psychological impact of quarantine and how to reduce it: rapid review of the evidence. The Lancet, 395(10227), 912-920. DOI

Brumbach, B. H., Figueredo, A. J., \& Ellis, B. J. (2009). Effects of harsh and unpredictable environments in adolescence on development of life history strategies. Human Nature, 20(1), 25-51. DOI 
Bui, T. (2020, May 1st). Aggressive testing and pop songs: how Vietnam contained the coronavirus. https:// www.theguardian.com/commentisfree $/ 2020 / \mathrm{may} / 01 /$ testing-vietnam-contained-coronavirus

Bundesministerium für Soziales, Gesundheit, Pflege und Konsumentenschutz [BSGPK] (2020, May

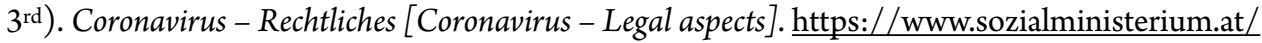
Informationen-zum-Coronavirus/Coronavirus---Rechtliches.html

Cawley, G. C., \& Talbot, N. L. C. (2010). On Over-fitting in Model Selection and Subsequent Selection Bias in Performance Evaluation. The Journal of Machine Learning Research, 11, 2079-2107.

Cígler, H., Cvrčková, A., Daňsovác, P., Hašto, J., Charvát, M., Ježek, S., Kaščáková , N., Lacinová, N., \& Seitl, M. (2019). Experiences in close relationships: České verze metod pro měření vazby vycházející z dotazníku ECR. E-psychologie, 13(4). https://e-psycholog.eu/pdf/Cigler_etal.pdf

Computational Story Lab (2020). Average Happiness for Twitter. https://hedonometer.org/timeseries/ en all/

Del Giudice, M., Gangestad, S. W., \& Kaplan, H. S. (2016). Life history theory and evolutionary psychology. In D. M. Buss (Ed.), The handbook of evolutionary psychology: Foundations (p. 88114). John Wiley \& Sons, Inc.. DOI

Demos, K. E., Heatherton, T. F., \& Kelley, W. M. (2012). Individual differences in nucleus accumbens activity to food and sexual images predict weight gain and sexual behavior. Journal of Neuroscience, 32(16), 5549-5552. DOI

Dhurandhar, E. J. (2016). The food-insecurity obesity paradox: a resource scarcity hypothesis. Physiology \& Behavior, 162, 88-92. DOI

Dodds, P. S., Harris, K. D., Kloumann, I. M., Bliss, C. A., \& Danforth, C. M. (2011). Temporal patterns of happiness and information in a global social network: Hedonometrics and Twitter. PloS one, 6(12), e26752. DOI

Duncan, L. A., Schaller, M., \& Park, J. H. (2009). Perceived vulnerability to disease: Development and validation of a 15-item self-report instrument. Personality and Individual differences, 47(6), 541-546. DOI

Dziennik Ustaw (2020), poz. 433-697 [Journal of Laws of the Republic of Poland]. http:// isap.sejm.gov.pl/isap.nsf

Eder, S. J., Steyrl, D., Stefańczyk, M., Pieniak, M., Molina, J. M., Pešout, O., Binter, J., Smela, P., Scharnowski, F., \& Nicholson, A. (2020, August 22). Predicting fear and perceived health during the COVID-19 pandemic using machine learning: A cross-national longitudinal study. DOI

Eder, S. J., Nicholson, A., Stefańczyk, M., Pieniak, M., Molina, J. M., Pešout, O., Binter, J., Smela, P., Scharnowski, F., \& Steyrl, D. (2020, September 14). Securing your relationship: Quality of intimate relationships during the COVID-19 pandemic can be predicted by attachment security. $\underline{\mathrm{DOI}}$

Emond, M., Ten Eycke, K., Kosmerly, S., Robinson, A. L., Stillar, A., \& Van Blyderveen, S. (2016). The effect of academic stress and attachment stress on stress-eaters and stressundereaters. Appetite, 100, 210-215. DOI

Enguix, S. (2020, March 22nd). Carrera por instalar hospitales de campaña en las ciudades más afectadas. La vanguardia. Retrived from http://hemeroteca.lavanguardia.com/preview/2020/03/22/ pagina33/296617044/pdf.html?search=IFEMA

Eurostat (2020, April 23rd). Population on 1 January (online data code:TPS00001). Retrieved from https:// ec.europa.eu/eurostat/databrowser/view/tps00001/default/table?lang=en

Fernández-Fuertes, A. A., Orgaz, B., Fuertes, A., \& Carcedo, R. (2011). La evaluación del apego romántico en adolescentes españoles: validación de la versión reducida del Experiences in Close Relationships-Revised (ECR-R). Anales de psicología, 27(3), 827-833.

Fogelholm, M., \& Kukkonen-Harjula, K. (2000). Does physical activity prevent weight gain-a systematic review. Obesity reviews, 1(2), 95-111. DOI

Fraley, R. C., Waller, N. G., \& Brennan, K. A. (2000). An item response theory analysis of self-report measures of adult attachment. Journal of Personality and Social Psychology, 78(2), 350. DOI

Franken, I. H., \& Muris, P. (2005). Individual differences in reward sensitivity are related to food craving and relative body weight in healthy women. Appetite, 45(2), 198-201. DOI

Garbe, L., Rau, R., \& Toppe, T. (2020). Influence of perceived threat of Covid-19 and HEXACO personality traits on toilet paper stockpiling. Plos one, 15(6), e0234232. DOI 
Geiker, N. R. W., Astrup, A., Hjorth, M. F., Sjödin, A., Pijls, L., \& Markus, C. R. (2018). Does stress influence sleep patterns, food intake, weight gain, abdominal obesity and weight loss interventions and vice versa?. Obesity Reviews, 19(1), 81-97. DOI

Geurts, P., Ernst, D., \& Wehenkel, L. (2006). Extremely randomized trees. Machine Learning, 63(1), 3-42. DOI

Griskevicius, V., Ackerman, J. M., Cantú, S. M., Delton, A. W., Robertson, T. E., Simpson, J. A., Thompson, M. E., \& Tybur, J. M. (2013). When the economy falters, do people spend or save? Responses to resource scarcity depend on childhood environments. Psychological Science, 24(2), 197-205. DOI

Hazan, C., \& Shaver, P. (1987). Romantic love conceptualized as an attachment process. Journal of Personality and Social Psychology, 52(3), 511-524. DOI

Hale, T., Webster, Anna Petherick, Toby Phillips, and Beatriz Kira (2020, May 18th). Oxford COVID-19 Government Response Tracker, Blavatnik School of Government. https://www.bsg.ox.ac.uk/research/ research-projects/coronavirus-government-response-tracker

Heinrichs, M., Baumgartner, T., Kirschbaum, C., \& Ehlert, U. (2003). Social support and oxytocin interact to suppress cortisol and subjective responses to psychosocial stress. Biological Psychiatry, 54(12), 1389-1398. DOI

Ileri-Gurel, E., Pehlivanoglu, B., \& Dogan, M. (2013). Effect of acute stress on taste perception: in relation with baseline anxiety level and body weight. Chemical Senses, 38(1), 27-34. DOI

Kerri, A., Young, A., Trapper, J., Gray, M., \& Powers, D.E. (2020). Use of Commercial Disinfectants to treat novel coronavirus (Covid-19) through oral administration or subdermal injection. https://ifunny.co/ picture/th-new-england-journal-of-medicine-use-of-commercial-disinfectants-ViqhYpvb7

Kim, J. U., Majid, A., Judge, R., Crook, P., Nathwani, R., Selvapatt, N., Lovendoski, J., Manousou, P., Thursz, M., Dhar, A., Lewis, H., Vergis, N., \& Lemoine, M. (2020). Effect of COVID-19 lockdown on alcohol consumption in patients with pre-existing alcohol use disorder. The Lancet Gastroenterology \& Hepatology, 5(10), 886-887. DOI

Lamson, A. L., Didericksen, K. W., Winter, A., Brimhall, A. S., \& Lazorick, S. (2019). Attachment, Parenting, and Obesogenic Behavior: A Dyadic Perspctive. Journal of Marital and Family Therapy, $00,1-16$. DOI

Laran, J., \& Salerno, A. (2013). Life-history strategy, food choice, and caloric consumption. Psychological science, 24(2), 167-173. DOI

Leech, T. G., \& Dias, J. J. (2012). Risky sexual behavior: a race-specific social consequence of obesity. Journal of Youth and Adolescence, 41(1), 41-52. DOI

Lieberman, L. S. (2006). Evolutionary and anthropological perspectives on optimal foraging in obesogenic environments. Appetite, 47(1), 3-9. DOI

Lubiewska, K., \& Van de Vijver, F. J. (2020). Attachment categories or dimensions: The Adult Attachment Scale across three generations in Poland. Journal of Social and Personal Relationships, 37(1), 233-259. DOI

Luo, J., Thomson, C. A., Hendryx, M., Tinker, L. F., Manson, J. E., Li, Y., Nelson, D. A., Vitolins, M. Z., Seguin, R. A., Eaton, C. B., Wactawski-Wende, J., \& Margolis, K. L. (2019). Accuracy of selfreported weight in the Women's Health Initiative. Public health nutrition, 22(6), 1019-1028. DOI

Mazza, C., Ricci, E., Biondi, S., Colasanti, M., Ferracuti, S., Napoli, C., \& Roma, P. A. (2020). Nationwide Survey of Psychological Distress among Italian People during the COVID-19 Pandemic: Immediate Psychological Responses and Associated Factors. International Journal of Environmental Research and Public Health, 17(9), 3165. DOI

Michaud, C. L., Kahn, J. P., Musse, N., Burlet, C., Nicolas, J. P., \& Mejean, L. (1990). Relationships between a critical life event and eating behaviour in high-school students. Stress Medicine, 6(1), 57-64. DOI

Ministerio de la Presidencia (2020). Real Decreto 463/2020, de 14 de marzo, por el que se declara el estado de alarma para la gestión de la situación de crisis sanitaria ocasionada por el COVID-19. Boletín Oficial del Estado, 67

Ministry of Health of the Czech Republic [MHCR] (2020, May 18). COVID-19 epidemic in the Czech Republic [Onemocnèní Aktuálně MZČR]. Ministerstvo zdravotnictví České republiky. https:// koronavirus.mzcr.cz/en/

Mullins, T. S., Campbell, E. M., \& Hogeveen, J. (2020). Neighborhood Deprivation Shapes MotivationalNeurocircuit Recruitment in Children. Psychological Science. DOI 
Nettle, D. (2010). Dying young and living fast: Variation in life history across English neighborhoods. Behavioral Ecology, 21(2), 387-395. DOI

Nettle, D., Andrews, C., \& Bateson, M. (2017). Food insecurity as a driver of obesity in humans: The insurance hypothesis. Behavioral and Brain Sciences, 40. DOI

Nettle, D., Joly, M., Broadbent, E., Smith, C., Tittle, E., \& Bateson, M. (2019). Opportunistic food consumption in relation to childhood and adult food insecurity: an exploratory correlational study. Appetite, 132, 222-229. DOI

Nisbett, R. E., \& Kanouse, D. E. (1969). Obesity, food deprivation, and supermarket shopping behavior. Journal of Personality and Social Psychology, 12(4), 289-294. DOI

Pedregosa, F., Varoquaux, G., Gramfort, A., Michel, V., Thirion, B., Grisel, O., Blondel, M., Prettenhofer, P., Weiss, R., Dubourg, V., Vanderplas, J., Passos, A., Cournapeau, D., Brucher, M., Perrot, M. \& Duchesnay, E. (2011). Scikit-learn: Machine learning in Python. The Journal of Machine Learning Research, 12, 2825-2830.

Petherick, A., Hale, T., Phillips, T., \& Webster, S. (2020, May $6^{\text {th }}$ ). Variation in government responses to COVID-19. Blavatnik school working paper. Retrieved from https://www.bsg.ox.ac.uk/research/ publications/variation-government-responses-covid-19

Popper, R., Smits, G., Meiselman, H. L., \& Hirsch, E. (1989). Eating in combat: a survey of US Marines. Military medicine, 154(12), 619-623. DOI

Prentice, A. M., \& Jebb, S. A. (2001). Beyond body mass index. Obesity Reviews, 2(3), 141-147. DOI

R Core Team (2017). R: A Language and Environment for Statistical Computing. R Foundation for Statistical Computing, Vienna, Austria. https://www.R-project.org

Redacció i agèncie la Vanguardia (2020, March 24th). Madrid guardarà cadàvers en una pista de gel pel collapse funerari. http://hemeroteca.lavanguardia.com/preview/2020/02/13/ pagina24/297014519/pdf.html?search=Palacio\%20de\%20hielo

Retana-Márquez, S., Vigueras-Villaseñor, R. M., Juárez-Rojas, L., Aragón-Martínez, A., \& Torres, G. R. (2014). Sexual behavior attenuates the effects of chronic stress in body weight, testes, sexual accessory glands, and plasma testosterone in male rats. Hormones and Behavior, 66(5), 766-778. $\underline{\mathrm{DOI}}$

Rothman, K. J. (2008). BMI-related errors in the measurement of obesity. International Journal of Obesity, 32(3), S56-S59. DOI

Scrivner, C. An Infectious Curiosity: Morbid Curiosity and Media Preferences During a Pandemic. Evolutionary Studies in Imaginative Culture, 5(1).

Simpson, J. A., \& Belsky, J. (2008). Attachment theory within a modern evolutionary framework. In: Cassidy, J., Shaver, P.R. [eds]. The Handbook of Attachment: Theory, Research, and Clinical Applications. 3rd. Guilford Press.

Simpson, J. A., \& Rholes, W. S. (2017). Adult attachment, stress, and romantic relationships. Current opinion in psychology, 13, 19-24. DOI

Sinha, R., \& Jastreboff, A. M. (2013). Stress as a common risk factor for obesity and addiction. Biological Psychiatry, 73, 827-835. DOI

Steger, I. (2020, March 2nd). Germans taking part in coronavirus panic-hoarding are doing a "Hamsterkauf". https://qz.com/1811000/hamsterkauf-germans-austrians-panic-buying-due-to-coronavirus/

Swaffield, J., \& Roberts, S. C. (2015). Exposure to cues of harsh or safe environmental conditions alters food preferences. Evolutionary Psychological Science, 1(2), 69-76. DOI

Tondo, L. (2020). Mafia distributes food to Italy's struggling residents. https://www.theguardian.com/world/ 2020/apr/10/mafia-distributes-food-to-italys-struggling-residents

Torres, S. J., \& Nowson, C. A. (2007). Relationship between stress, eating behavior, and obesity. Nutrition, 23(11-12), 887-894. DOI

Troisi, J. D., Gabriel, S., Derrick, J. L., \& Geisler, A. (2015). Threatened belonging and preference for comfort food among the securely attached. Appetite, 90, 58-64. DOI

United Nations [UN] (2020). Policy Brief: The Impact of COVID-19 on Food Security and Nutrition. https://reliefweb.int/sites/reliefweb.int/files/resources/ sg_policy_brief_on_covid_impact_on_food_security.pdf 
Eder, S.J. et al. (2020). Food insecurity and body weight during a pandemic Human Ethology, 35, 122-136

Velázquez, J. (2020, March 31st). Grieving and goodbyes difficult as COVID-19 lockdown compounds pain in Spain. https://www.euronews.com/2020/03/30/coronavirus-grieving-and-goodbyes-difficult-aslockdown-compounds-the-pain-of-those-left-b

Vigil, J. M., \& Geary, D. C. (2006). Parenting and community background and variation in women's lifehistory development. Journal of Family Psychology, 20(4), 597. DOI 